\title{
Factors related to road accidents in Palembang, South Sumatera, Indonesia
}

\author{
Desheila Andarini' ${ }^{1}$, Anita Camelia ${ }^{2}$, Mochammad Malik Ibrahim ${ }^{3}$ \\ ${ }^{1,2}$ Department of Occupational Health and Safety, Faculty of Public Health, Universitas Sriwijaya, Indonesia \\ ${ }^{3}$ Department of Geological Engineering, Faculty of Engineering, Universitas Sriwijaya, Indonesia
}

\begin{tabular}{l} 
Article Info \\
\hline Article history: \\
Received Dec 3, 2020 \\
Revised May 17, 2021 \\
Accepted Jun 18, 2021 \\
\hline
\end{tabular}

Keywords:

Accident

Palembang

Road safety

Road traffic injuries

\begin{abstract}
Road traffic injuries are a major public health problem and a leading cause of death and injury worldwide. More than $90 \%$ of all road deaths occur in lowand middle-income countries, which own less than half of the world's vehicles. The research aimed was to identify the factors related to road accidents in Palembang, Indonesia. The research method used was qualitative approach by using in-depth interviews and observation. This research was conducted from August to December, 2019. The results showed that the factors related to road accidents were human factor, environmental and climatic factor. From this research, the working areas identified as accidentprone zone were Sukarami II and Ilir Barat I Police Station. Referring to the accident and interviews, it is known that the road locations that have the highest casualties were in the road of Kolonel H. Barlian, Jendral Sudirman, Demang Lebar Daun, Ahmad Yani, and Soekarno Hatta. The conclusion was the accident-prone zone located on the main arterial road in Palembang City, Jendral Sudirman Road with a total of 81 cases of traffic accidents in the last three years that need further investigation to minimize traffic injury.
\end{abstract}

This is an open access article under the CC BY-SA license.

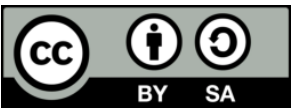

\section{Corresponding Author:}

Desheila Andarini

Faculty of Public Health

Universitas Sriwijaya

Public Health Building, Palembang-Prabumulih KM. 32 Road, Indralaya, South Sumatera, Indonesia

Email: desheila_andarini@fkm.unsri.ac.id

\section{INTRODUCTION}

Road accidents pose a serious problem for the economy, especially in low and middle income countries, where the death rates due to road injuries are three times higher than in high-income countries. At a worldwide level, road accidents are the leading cause for deaths among young people aged between 5 and 29, and the eighth cause for all the age groups, above HIV/AIDS, tuberculosis and diarrhoeal diseases [1]. Effective prevention of traffic accidents is an important focus of attention for society because it is related to human life, economic impacts and social impacts [2].

Road traffic is the ninth leading cause of death and is responsible for $2.2 \%$ of all deaths globally and road accidents are the lead g cause of death among young people aged 15-29, as well as the second leading cause of death worldwide among young people 5-14. Every year nearly 400,000 people under 25 die on the world's roads, averaging over 1,000 a day. More than $90 \%$ of all road deaths occur in low- and middleincome countries, which own less than half of the world's vehicles. According to World Health Organization (WHO) data published in 2018, Road Traffic Accidents Deaths in Indonesia reached 41,862 or 2.46\% of total deaths. The age adjusted death rate is 18.01 per 100,000 of population ranks . 
Road accidents cost low- and middle-income countries USD \$ 65 billion per year, exceeding the total amount received in development assistance. If no action is taken, road traffic injuries are predicted to become the fifth leading cause of death by 2030 [3]. The estimated road traffic death rate in South East Asian Region is 18.5 per 100,000 population showed that Thailand has the highest rate of 38.1 per 100,000 population followed by Timor-Leste (19.5), India (18.9), Indonesia (17.7) and Nepal (16.0). Maldives had the lowest rate with only 1.9 per 100,000 population. The rate is higher in middle-(19.5) than in low-income countries (12.7) [4]. In Iran, the annual mortality rate of traffic accidents was 44 in one hundred thousand of population [5]. Compared to 2018, in 2019 the number of accidents on Polish roads decreased by $4.4 \%$ and the number of people injured in road accidents by $5 \%$. Unfortunately, the number of people killed in road accidents also increased by $1.6 \%$ [6]. The numbers of fatalities have increased annually and road authority should seriously consider conducting programs or activities to periodically monitor, restore of improve road infrastructure [7].

Accidents that generally occur due to various causes collectively: humans, road conditions and road completeness. Humans are the dominant factor causing traffic accidents, although in fact road conditions can also be one of the causes of traffic so that in order to prevent actions that endanger road traffic safety it is necessary to be equipped with various road fittings to help regulate traffic flow, road markings, traffic light lanes, safety fences, and other traffic engineering [8]. Many factors underlie the rapid increase of traffic accidents, which has become a major social problem. For example, in cities in South East Asian countries, pedestrians, motorcycles, automobile vehicles, and vehicles peculiar to South Asian countries (e.g., motorcycle taxi and three-wheeler tuk-tuks) use the road in a chaotic manner. The road traffic infrastructure is underdeveloped and social institutions such as a driving license system are not well established. Furthermore, education measures to improve people's awareness of road safety are not fully developed and implemented. These factors are intertwined in a complex manner, worsening traffic congestion and accidents [9]. Physical inventories, measurements, attributes of the street geometrics, physical features (trees, curb and gutters, access points, utilities, intersections, traffic signs, pavement markings, and signal systems also identified as potential safety hazards in the road [10]. Moreover, work-related vehicle crashes are a common cause and classified as occupational injury [11].

According to the Central Bureau of Statistics, Palembang city with the status as the provincial capital has a fairly dense population, 1,535,900 people with a male population composition of 50.07 percent and a female population of 49.93 percent. The population is quite dense and the rapid development causes high population mobility which can increase the number of traffic accidents. This can be seen from the police records of the Republic of Indonesia (RI), that in 2013 there were 101,037 traffic accidents in Indonesia, where the number of accidents was 25,157 people, compared to 2012 which reached 27,441 deaths while in 2011 the number of fatalities reached 32,657 lives and in 2010 the number of casualties reached 19,873 people. In 2017, there was 329 total accident cases in Palembang with material lost as much as IDR $1,136,000,000$, there was 367 accident in 2018 with total material lost IDR 925,100,000, increased to 653 cases in 2019 with total material lost IDR 1,113,750,000 [12].

Traffic accidents that often occur which have accident categories such as motorbike and car driver accidents, traffic accidents also have various factors such as human factors, environmental factors, road factors and vehicle factors that can cause death and material loss, based on background descriptions. The results of preliminary observations from Metropolitan Police in Palembang show that the number of traffic accidents in Palembang is remain high from 2015 until 2019 the data increased from 574 into 653 cases. According to the increased accident cases in Palembang from year to year, it is important to conduct research on the Factors related to Road Accidents in Palembang, South Sumatra, Indonesia. The novelty from this research was identified the accident-prone zone area in Palembang.

\section{RESEARCH METHOD}

This research was carried out along the main road in Palembang started from August to November 2020. This research was a qualitative research with observation, interviews, and accident data document review. Qualitative methods are used to understand the phenomenon of what research subjects experience holistically, and by means of descriptions in the form of words and language [13]. Sources of information in this study are consisted of eight informants from traffic road users in prone areas and the department of transportation as well as representatives from the police. Determining the source of this information is done by purposive sampling. The identification of potential hazards, risks and accident data from informants are taken from people who know and understand the problems related to the hazard by in-depth interview.

In this study, primary data collection was carried out by interviewing using in-depth interview guidelines and direct observation. Secondary data in this study are the profile of the research site and other supporting documents. The data collection instrument used in this study was an in-depth interview guide 
referred to hazard identification and risk assessment method (HIRARC) containing questions to collect information according to the researcher's objectives, observation sheet checklists, cameras and stationery. The hazard identification process was carried out based on the primary data, then a risk analysis was carried out and a risk ranking was carried out based on the guidance from the qualitative table, and then narrated in the form of a sentence. Risk was classified into High, Medium and Low based on HIRARC. Below are table for the frequency as shown in Table 1, the severity as shown in Table 2 and the risk ranking as shown in Table 3 [14], [10].

Table 1. How often are these problems likely to cause collisions?

\begin{tabular}{cc}
\hline Frequency & Description \\
\hline Frequent & One or more times per week \\
Probable & Once or more per year (but less than once a week) \\
Occasional & Once every five or ten years \\
Never & Less than once in ten years \\
\hline
\end{tabular}

Table 2. Results of the type of collision resulting in what is the likely severity?

\begin{tabular}{ccc}
\hline Severity & Description & Example \\
\hline Fatality & The chances of death are majority & Speeding, streak on the road \\
Serious & Possible death or serious injury & High or medium speed vehicle/vehicle collision \\
Minor & Possible minor injuries & Collisions that occur on vehicles at low speed \\
Limited & Probably no injury or just property damage & $\begin{array}{c}\text { Multiple crashes of oncoming vehicles at low speed. } \\
\end{array}$
\end{tabular}

Table 3. Improvement approach

\begin{tabular}{cc}
\hline Risk & Recommended improvement \\
\hline Very high & Must be corrected \\
High & It must be repaired or the risk is significantly reduced if the cost even though the costs of repairs are high \\
Medium & It must be repaired or the risk is significantly reduced if repair costs are moderate, but not high \\
Low & It must be repaired or the risk is significantly reduced if the cost of repairs is low \\
\hline
\end{tabular}

Data processing obtained from the results of in-depth interviews with informants was carried out in the following stages: collect all data obtained from informants through in-depth interviews, from the data collected, a transcript is made, which is to record all the data obtained, data was sorted by data grouping according to each category and presenting a summary of data in the form of a matrix or table from the results of in-depth interviews.

\section{RESULTS AND DISCUSSION}

\subsection{Number of road accidents}

Table 4 shows are the number of road accidents in Palembang from 2015 to 2020 that consisted of fatality, major injury and minor injury.

Table 4. Number of road accidents in Palembang 2015-2020

\begin{tabular}{|c|c|c|c|c|c|}
\hline \multirow[t]{2}{*}{ No } & \multirow[t]{2}{*}{ Year } & \multicolumn{3}{|c|}{ Total number of road accident } & \multirow[t]{2}{*}{ Total case } \\
\hline & & Fatality & Major injury & Minor injury & \\
\hline 1 & 2015 & 117 & 349 & 321 & 574 \\
\hline 2 & 2016 & 110 & 230 & 289 & 453 \\
\hline 3 & 2017 & 78 & 177 & 220 & 329 \\
\hline 4 & 2018 & 106 & 95 & 377 & 367 \\
\hline 5 & 2019 & 77 & 125 & 745 & 653 \\
\hline 6 & 2020 & 23 & 41 & 324 & 252 \\
\hline \multicolumn{2}{|c|}{ Total } & 511 & 1,017 & 2,276 & 2,628 \\
\hline
\end{tabular}

Based on the Table 4, the criteria with the highest risk level death in 2015 with 117 people, major injury in 2015 with 349 people, minor injury in 2019 with 745 people. For cases of accident in the city of Palembang with accident cases then the most occurred in 2019 with a total of 653 people, so the total in Palembang from 2015-2020 totaled 2,628 incidents and accident with a severity of 2,276 people. 
The road accident based on age divided into excutant and victim ranging from 0-15, 16-20, 21-30, 31-40, 41-50 and 51 years old above are presented in the Table 5.

Table 5. Total of road accidents based on age in Palembang 2015-2020

\begin{tabular}{cccccccccccccc}
\hline No & Year & \multicolumn{1}{c}{ Executant } & \multicolumn{1}{c}{ Victim } \\
& & $0-15$ & $116-20$ & $221-30$ & $331-40$ & $441-50$ & $551>$ & $00-15$ & $116-20$ & $221-30$ & $331-40$ & $441-50$ & $51>$ \\
\hline 1 & 2015 & 39 & 70 & 96 & 53 & 45 & 43 & 14 & 18 & 182 & 185 & 119 & 130 \\
2 & 2016 & 17 & 54 & 74 & 68 & 51 & 27 & 63 & 93 & 169 & 151 & 103 & 85 \\
3 & 2017 & 10 & 33 & 53 & 41 & 37 & 26 & 35 & 58 & 118 & 83 & 95 & 74 \\
4 & 2018 & 19 & 50 & 51 & 27 & 40 & 53 & 61 & 77 & 102 & 81 & 111 & 138 \\
5 & 2019 & - & 101 & 127 & 128 & 90 & 60 & 47 & 178 & 230 & 221 & 171 & 97 \\
6 & 2020 & 3 & 23 & 29 & 32 & 37 & 69 & 15 & 25 & 78 & 47 & 82 & 91 \\
\multicolumn{2}{c}{ Total } & 88 & 331 & 430 & 349 & 220 & 278 & 535 & 539 & 879 & 768 & 681 & 615 \\
\hline \multicolumn{2}{l}{ Tource }
\end{tabular}

Based on the Table 5, accident with an age range criteria of 31-40 years and 21-30 years in the category caused by victims with a total of 879 and 768 incidents from 2015-2020, for the category of perpetrators with a range of 21-30 years and 31 years. 40 years with a total incidence of 430 and 349 incidents from 2015-2020. Data on vehicles involved in Traffic Accident were consisted of motorcycle, bus, passenger, load and other from year 2015 to 2020 are presented in Table 6.

Table 6. Risk level

\begin{tabular}{ccccc}
\hline & Frequent & Probable & Occasional & Never \\
\hline Fatality & Very heavy & Very heavy & Very heavy & High \\
Serious & Very heavy & Very heavy & High & Medium \\
Minor & Very heavy & High & Medium & Low \\
Limited & High & Medium & Low & Low \\
\hline
\end{tabular}

Based on the Table 7, the highest number of accidents occurred in motorcycle users with the highest incidence occurring in 2019 with 736 incidents and 3,054 incidents in the last five years.

The road with the highest accident cases in eight main roads in Palembang were taken in Jendral Sudirman, H.A Bastari, Soekarno Hatta, Demang Lebar Daun, Achmad Yani, Yusuf Singadekane, Kol. H.Barlian, Abdul Rozak is presented in Table 8.

Table 7. Data on vehicles involved in traffic accidents 2015-2020

\begin{tabular}{cccccccccc}
\hline No & Year & Motorcycle & \multicolumn{3}{c}{ Bus } & \multicolumn{2}{c}{ Passenger } & \multicolumn{3}{c}{ Load } & Other \\
& & & Public & Private & Public & Private & Public & Private & \\
\hline 1 & 2015 & 696 & - & 12 & 14 & 254 & - & 84 & 50 \\
2 & 2016 & 552 & 12 & 1 & 4 & 173 & - & 92 & 67 \\
3 & 2017 & 382 & - & 3 & 4 & 121 & - & 79 & 15 \\
4 & 2018 & 414 & - & 1 & 4 & 101 & - & 79 & 5 \\
5 & 2019 & 736 & - & 2 & 8 & 115 & - & 59 & 14 \\
6 & 2020 & 274 & - & - & - & 41 & - & 13 & 4 \\
\multicolumn{2}{l}{ Total } & 3.054 & 12 & 19 & 34 & 805 & - & 406 & 155 \\
\hline
\end{tabular}

Table 8. Road with the highest accident cases in 2017-2019

\begin{tabular}{cccccc}
\hline No & Road & Year & Accident case \\
& & 2017 & 2018 & 2019 & \\
\hline 1 & Jendral Sudirman & 23 & 22 & 36 & 81 \\
2 & H.A.Bastari & 10 & 16 & 18 & 44 \\
3 & Soekarno Hatta & 16 & 10 & 26 & 52 \\
4 & Demang Lebar Daun & 19 & 11 & 25 & 55 \\
5 & Achmad Yani & 13 & 16 & 18 & 47 \\
6 & Yusuf Singadekane & 13 & 14 & 10 & 37 \\
7 & Kol.H.Barlian & 9 & 24 & 28 & 61 \\
8 & Abdul Rozak & 11 & 14 & 7 & 32 \\
\hline
\end{tabular}

Source: Metropolitan Police of Palembang 
Based on the Table 8, it shows that Jendral Sudirman is a road that often occurs then the highest in 2019 with a total of 36 cases and in the last three years there have been 81 cases on Jendral Sudirman Road.

\subsection{The causes of road accident}

The causes of road accident according to the in-depth interview with the informants that consisted of violation and main cause on the road, here are interview with the respondent about the violation:

"Violations that are often committed by the local community are such as speeding, especially high school or vocational high school students and vocational high school students, as well as often breaking red lights and passing forbidden roads." (Informant 4)

"Violations that are often committed by the local community are like speeding, but the ones who do it most often are like high school teenagers." (Informant 5)

"Violations that are often committed by people who often cross this road, such as going against the direction or perpoden, are often done to accelerate towards intersections and detours." (Informant 6)

Here are interview with the respondent about the main cause of road accident:

" The main cause is running a red light and not seeing potholes due to speeding, and also if you turn right from the radial direction, now that is the most risky, sometimes accidents often because you avoid the police who stop you." (Informant 1)

"The cause of the traffic accident is of course the people are often speeding and there has also been a collision at the intersection of three red lights because of the straight road and running red lights and passing the forbidden road in front of the Amaris Hotel area." (Informant 2)

"The cause of the traffic accident was due to the lack of potholes and road signs installed." (Informant 3)

From the interview it is known that the main cause of road accident is categorized as environmental factor, human error including violation and climatic factor. For environmental factor, the main cause is due to lack of potholes, road signs and lamp. For human factor, the main cause is due to the violation such as driving in high speeding, breaking red light, passing forbidden road. For climatic factor, the main cause is due to raining that make the road become wet and slippery.

\subsection{Road risk classification}

According to the hazard identification in the interview and observation, the road was classified into low, medium and high as shown in Table 9.

Table 9. Road risk classification

\begin{tabular}{|c|c|c|c|c|}
\hline \multirow[t]{2}{*}{ No } & \multirow[t]{2}{*}{ Road } & \multicolumn{3}{|c|}{ Risk classification } \\
\hline & & Low & Medium & High \\
\hline 1 & Jendral Sudirman & & & \\
\hline 2 & Soekarno Hatta & & & \\
\hline 3 & Kol.H.Barlian & & & \\
\hline 4 & Achmad Yani & & & \\
\hline 5 & Yusuf Singadekane & & & \\
\hline 6 & Demang Lebar Daun & & & \\
\hline 7 & H.A Bastari & & & \\
\hline 8 & Abdul Rozak & & & \\
\hline
\end{tabular}

Based on the Table 9, the top three highest risks are consisted of Jenderal Sudirman, Kolonel H. Barlian and Demang Lebar Daun road with high number of the victim consisted of truck driver with overload capacity. According to the observation on Sudirman Road, it is known that there are still many roads with potholes and holes near the curves and straight roads considering that Sudirman is a protocol road in Palembang. For road markings, There are several road markings that cannot be seen, especially at the intersection to the bird market. For traffic signs, there are incomplete traffic signs such as crossing signs, prohibited parking and warning signs.

For Demang Lebar Daun Road, there is a sloping road in the area close to the Dunkin Donut which is tilted to the left and also has potholes in almost every direction around the road. Along the road, there are 
cut markings for a distance of 100-300m from the Demang Lebar Daun red light intersection and no signs are installed slowly in the area near Dunkin Donut due to the sloping road and the vehicle speed limit signpost has not been installed.

There are several points on Kolonel Haji Burlian's road that are no longer feasible to pass because they have holes and if they are patched they will only become bumpy, there are also road cuts because the road will be patched. For road markings, there are several points on Colonel H. Burlian street that have quite faded road markings, moreover the left and right signs and broken markers for the middle road. The road has almost complete signs, but there is no signpost for speed limit vehicles, warning signals for entry and exit of project vehicles and convex mirrors for intersections. For street lights in Colonel H. Burlian, there is mostly not lit when it is approaching the road to fly over. From the interview and the observation, it is known that the highest accident on the road is consisted of Jendral Sudirman, Demang Lebar Daun and Kolonel Haji burlian road.

\subsection{Discussion}

Road traffic safety is a significant public health issue. Unfortunately, traffic crashes are frequent, as well as the deaths and injuries caused [15]. The frequencyof road accident in Palembang is increased from 2015 to 2020 with totaled 2,628 incidents and accident with a severity of 2,276 people. The number of fatal and disabling road accident happening is increasing day by day and is a real public health challenge for all the concerned, thus awareness creation, strict implementation of traffic rules, and scientific engineering measures are the need of the hour to prevent this public health catastrophe [16]. According to the study conducted by Hema [16] in India that accident analysis over the years shows that nearly 130,000 people have died on roads, constantly being on the top world's death rate list, mainly due to poor road condition and violation of rules by drivers. The main cause of road accident is categorized as environmental factor, human error including violation and climatic factor. The research of Rolison showed that both expert views of police officers and lay views of the driving public closely approximated the typical factors associated with the collisions of young and older drivers, as determined from official accident records [17]. The probability that the accident is fatal or serious decreases with population size and the probability that it is minor, increases sub linearly [1].

For environmental factor, the main cause is due to lack of potholes, road signs and lamp. According to Law No.38 of 2004, roads are one of the transportation infrastructure and are an important element in the creation of driving and traffic safety. In general, good weather conditions and night accidents increase severity. Moreover, crash types are consistently affecting accident severity [2]. Road includes complementary buildings and their equipment intended for traffic, which are on the surface of the ground, above the ground level, below the ground and/or water, and above the water level, except for railways, lorries and cable roads. 'Geometric design' variables and 'pavement condition' variables are the two most important factors affecting accident rates [18]. The physical environmental factors that cause traffic accidents is consisted of potholes, damaged roads, wet/slippery roads, and the dark path. The study contends that increased exposure and night-time travel increase road crashes, whilst expansion of road infrastructure is inversely related to road accidents. An increase in both population density and exposure leads to increased fatalities [19].

For human factor, the main cause is due to the violation such as driving in high speeding, breaking red light, passing forbidden road. From several researches and field studies, it can be concluded that traffic accidents can be influenced by human factors, vehicles and the road environment, as well as the interaction of Human Factor. Humans as road users, pedestrians and vehicle drivers. These pedestrians are victims of accidents and can also be the cause of accidents. The driver of the vehicle is the main cause of accidents, so it is paid attention most often. The main causes were careless driving and drunk-driving [20]. Human factor is the most dominant factor in accidents. In the case of Cambodia, speeding by young people remains the major cause of road deaths [21]. Almost all accidents are preceded by violations of traffic signs. The human factor in a vehicle collision includes all factors related to the behavior of drivers and other road users that can contribute to a collision. Vehicles can be a factor causing accidents if they cannot be controlled properly, as a result of technical conditions that are not roadworthy or their use is not in accordance with the provisions. It need regulation for speed especially in motorcycle. Twenty $m p h(32.2 \mathrm{~km} / \mathrm{h})$ speed limits across urban areas are becoming a widespread tool for public health and road danger reduction globally [22]. However, the human behaviour factors are not the only indicators of the road safety level because it enhances the multidimensional system approach of defining the road safety [23]. The fatal accidents don't completely rely on the driver's fault, other cases like vehicle problems, pedestrians or other vehicle issues can also lead to fatal accidents [24].

For climatic factor, the main cause is due to raining that make the road become wet and slippery. Rain affects vehicle work such as longer braking distances, slippery roads, and shorter visibility. During the rainy season, the potential for traffic accidents is greater, which generally occur due to visual disturbances 
during heavy rain, or roads that are flooded with water resulting in a hydroplaning effect, in which tires do not tread directly on the surface of the asphalt because they are coated with water. Road Safety Audit is needed for further investigation. An important factor determining the effectiveness of the Road Safety Audit was that the Road Safety Audit recommendations were implemented shortly after the Road Safety Audit was completed [25]. Based on Castillo study, it is known that a higher traffic accident rate for foreign drivers and indicate that tourism traffic safety is a relevant topic that should be incorporated into road safety policy planning [26].

Transport poses a public health risk and the burden is greatest on the poorest in society [27]. The highest accident on the road is consisted of Jendral Sudirman, Demang Lebar Daun and Kolonel Haji Burlian road. The top three highest risk of road with high number of the victim consisted of truck driver with overload capacity. It is in line with Ghaleh [27], study that describe one of the most important problems in the road fleet transportation of hazardous materials is truck accidents in which the main influential factors are the type of truck and its safety conditions. Truck was the most involved vehicle in the road accident which is $39 \%$ of the total number of vehicles whereas, bus involved is $21 \%$ road accidents [28].

Road safety inspection looks at all structures of importance for road safety and all phenomena occurring on roads and in the safety zone, and in particular: geometry of roadway, pavements, cycle paths, pavements on road sections, shoulders, batters, ditches, culvert walls and retaining walls, geometry of roadway, pavements, cycle paths within junctions and interchanges, horizontal and vertical signage, traffic control, traffic management, lateral obstacles (trees, shrubs), barriers, rails, fencing and other road safety furniture, road frame drainage (central reservation, kerbside drainage, batter drainage), level crossings, bridges, viaducts, tunnels, animal passes, visibility in areas of exits, junctions, service areas, interchanges, visibility in between interchanges, road lighting, other elements of infrastructure in the safety zone (e.g. advertising, fencing, noise barriers [29].

Areas in the road transportation safety program include matters that are closely related to road transportation safety, such as in the road sector which includes the following programs: i) inventory of road service levels and their problems; ii) preparation of plans and implementation programs and determination of road service levels; iii) planning, building and optimizing the use of road segments; iv) improving the geometric area of roads and road intersections; v) determining road sections for each road section; vi) testing road function feasibility according to safety and traffic comfort standards; vii) developing systems information and communication in the field of road infrastructure. Other fields containing road traffic and transportation facilities and infrastructure include the following programs: i) road traffic and road transportation facilities and infrastructure; ii) traffic management and engineering; iii) motor vehicle roadworthiness and roadworthiness; iv) public transportation licensing; v) development of information systems and communications in the field of road traffic and transportation infrastructure; vi) guidance. Human resource constraints as soon as possible should be given attention, even training and socialization to people who do not know the importance of road transportation safety, besides providing attractive facilities so that people are enthusiastic about participating in the socialization carried out by the government [30].

\section{CONCLUSION}

This paper has explored the increasing number of traffic accidents as public health risks in Palembang. Based on the result of analysis, it can be concluded that the identified factors were human factors, environmental factors, climatic factors and vehicle factors. Traffic accidents in Palembang majority occured in motorbike users with a total of 3,054 cases in the past five years and vulnerable vehicle users are ranging by the age of 31-40 years. Referring to the accident and interviews, it is known that the road locations that have the highest casualties were in the road of Kolonel H. Barlian, Jendral Sudirman, Demang Lebar Daun, Ahmad Yani, and Soekarno Hatta. This result is also supported by the result of accident statistic data that the road in Palembang that has the highest traffic accident cases is Jendral Sudirman Road with a total of 81 cases of traffic accidents in the last three years, it is indicates as prone zone area and then classified as an accident prone zone. In order to control the accident, the government should make integrated program among Police, Department of Transportation and Public Works Service to initiate Road Safety Program especialy to conduct regular maintenance of road infrastructure so that congestion and accidents are avoided due to inadequate road conditions.

\section{ACKNOWLEDGEMENTS}

Thank to Lembaga Penelitian dan Pengabdian Masyarakat Universitas Sriwijaya for fully funding of this research. 


\section{REFERENCES}

[1] C. Cabrera-Arnau, R. P. Curiel, and S. R. Bishop, "Uncovering the behaviour of road accidents in urban areas," $R$. Soc. Open Sci., vol. 7, no. 4, 2020, doi: 10.1098/rsos.191739.

[2] Y. George, T. Athanasios, and P. George, "Investigation of road accident severity per vehicle type," Transportation Research Procedia, vol. 25, no. 1, pp. 2081-2088, 2017, doi: 10.1016/j.trpro.2017.05.401.

[3] Association for Safe International Road Travel, "Annual Global Road Crash Statistics," 2018. [Online]. Available : https://www.asirt.org/safe-travel/road-safety-facts/

[4] World Health Organization, "Regional strategy for road safety in South-East Asia," 2015, [Online]. Available: https://apps.who.int/iris/bitstream/handle/10665/177997/SEA-Injuries 24.pdf;jsessionid=3F5297168AE683FF3FBCEC32F2C1602A?sequence $=1$.

[5] S. M. Mahdiyan, K. A. Asgari, and M. Ranjbar, "Cost for traffic accident related injuries and its comparison it with the national standard: A case study in Iran,” Bali Med. J., vol. 7, no. 2, 2018, doi: 10.15562/bmj.v7i2.616.

[6] D. Frej and K. Ludwinek, "Analysis of road accidents in 2002-2019 on the example of poland," Archiwum Motoryzacji, vol. 89, no. 3, pp. 5-18, 2020.

[7] N. Samsuddin and M. I. Mohd Masirin, "Assessment of road infrastructures pertaining to Malaysian experience," MATEC Web Conf., vol. 47, 2016, doi: 10.1051/matecconf/20164703010.

[8] A. Mahardianto, “Audit keselamatan jalan di ruas bts. banyumas tengah - kebumen km 171 - 172 semarang," 2015.

[9] Commission for Global Road Safety, "Making roads safe: Time for action," 2011. [Online]. Available: http://www.makeroadssafe.org/publications/Documents/mrs_iii_report_lr.pdf.

[10] J. R. Jones and J. R. Jones, "A Method to Quantify Road Safety Audit Data and Results by," Thesis, Utah State University, 2013.

[11] R. Mitchell, R. Friswell, and L. Mooren, "Initial development of a practical safety audit tool to assess fleet safety management practices," Accid. Anal. Prev., vol. 47, pp. 102-118, 2012, doi: 10.1016/j.aap.2012.01.021.

[12] K. D. Lantas, "Accident Data Report in South Sumatra," Palembang.

[13] L. Moleong, Metodologi Penelitian Kualitatif Edisi Revisi. Bandung: PT. Remaja Rosdakarya, 2010.

[14] M. Idrus, B. Hj, N. Athirah, B. Mohamad, and N. B. Samsuddin, "Analysis of road infrastructural audits along jalan batu pahat- kluang malaysia: a case study analysis of road infrastructural audits along jalan batu pahat - kluang malaysia : a case study," ARPN Journal of Engineering and Applied Sciences, no. 11, no. 24, pp. 14101-14105, 2016.

[15] A. Jovic Vranes, V. Bjegovic Mikanovic, J. Milin Lazovic, and V. Kosanovic, "Road traffic safety as a public health problem: Evidence from Serbia," J. Transp. Heal., vol. 8, pp. 55-62, 2018, doi: h10.1016/j.jth.2017.12.005.

[16] S. Gopalakrishnan, "A public health perspective of road traffic accidents," J. Fam. Med. Prim. care, vol. 1, no. 2, pp. 144-150, Jul. 2012, doi: 10.4103/2249-4863.104987.

[17] J. J. Rolison, S. Regev, S. Moutari, and A. Feeney, "What are the factors that contribute to road accidents? An assessment of law enforcement views, ordinary drivers' opinions, and road accident records," Accid. Anal. Prev., vol. 115, no. February, pp. 11-24, 2018, doi: 10.1016/j.aap.2018.02.025.

[18] M. G. Karlaftis and I. Golias, "Effects of road geometry and traffic volumes on rural roadway accident rates," Accid. Anal. Prev., vol. 34, no. 3, pp. 357-365, May 2002, doi: 10.1016/S0001-4575(01)00033-1.

[19] T. Mphela, "Causes of road accidents in botswana: An econometric model," J. Transp. Supply Chain Manag., vol. 14, pp. 1-8, 2020, doi: 10.4102/jtscm.v14i0.509.

[20] C. Wangdi, M. S. Gurung, T. Duba, E. Wilkinson, Z. M. Tun, and J. P. Tripathy, "Burden, pattern and causes of road traffic accidents in Bhutan, 2013-2014: a police record review," Int. J. Inj. Contr. Saf. Promot., vol. 25, no. 1, pp. 65-69, 2018, doi: 10.1080/17457300.2017.1341930.

[21] Y. Kitamura, M. Hayashi, and E. Yagi, "Traffic problems in Southeast Asia featuring the case of Cambodia's traffic accidents involving motorcycles," IATSS Res., vol. 42, no. 4, pp. 163-170, 2018.

[22] A. Bornioli, I. Bray, P. Pilkington, and E. L. Bird, "The effectiveness of a 20 mph speed limit intervention on vehicle speeds in Bristol, UK: A non-randomised stepped wedge design," J. Transp. Heal., vol. 11, pp. 47-55, 2018, doi: 10.1016/j.jth.2018.09.009.

[23] A. K. Jameel and H. Evdorides, "Developing a safer road user behaviour index," IATSS Res., no. xxxx, 2020, doi: 10.1016/j.iatssr.2020.06.006.

[24] D. Hema and D. Assistant, "Road Accident Analysis in Kerala and Location Based Severity Level Classification Using Decision Tree Algorithm,” vol. XIV, no. I, pp. 41-50, 2021.

[25] S. Vardaki, F. Papadimitriou, and P. Kopelias, "Road safety audit on a major freeway: implementing safety improvements," Eur. Transp. Res. Rev., vol. 6, no. 4, pp. 387-395, 2014, doi: 10.1007/s12544-014-0138-0.

[26] J. I. Castillo-Manzano, M. Castro-Nuño, L. López-Valpuesta, and F. V Vassallo, "An assessment of road traffic accidents in Spain: the role of tourism," Curr. Issues Tour., vol. 23, no. 6, pp. 654-658, Mar. 2020, doi:

[27] N. Christie, "Why we need to view road safety through a public health lens?," Transp. Rev., vol. 38, no. 2, pp. 139141, Mar. 2018, doi: 10.1080/01441647.2018.1411226.

[28] M. Islam, R. Bin Ali, and F. K. Chowdhury, "Road Accident Analysis and Prevention Measures of RajshahiSirajganj Highway in Bangladesh," World Scientific News, vol. 126, no. April, pp. 209-221, 2019.

[29] K. Jamroz, M. Budzyński, W. Kustra, L. Michalski, and S. Gaca, "Tools for road infrastructure safety management -Polish experiences," Transp. Res. Procedia, vol. 3, no. July, pp. 730-739, 2014, doi: 10.1016/j.trpro.2014.10.052.

[30] J. J. Rolison, S. Regev, S. Moutari, and A. Feeney, "What are the factors that contribute to road accidents? An assessment of law enforcement views, ordinary drivers' opinions, and road accident records," Accid. Anal. Prev., 2018, doi: 10.1016/j.aap.2018.02.025. 